Copyright (C) 2020 University of Bucharest Printed in Romania. All rights reserved

ISSN print: $1224-5984$

ISSN online: $2248-3942$
Rom Biotechnol Lett. 2020; 25(2): 1320-1327

doi: $10.25083 / \mathrm{rbl} / 25.2 / 1320.1327$

Received for publication, October, 2, 2018

Accepted, January, 11, 2019

Original paper

\title{
Development of ultrasonic extracts with strong antioxidant properties from red onion wastes
}

\author{
SIMONA OANCEA ${ }^{1 *}$, MARIA RADU ${ }^{2}$, HOREA OLOSUTEAN ${ }^{2}$ \\ 1"Lucian Blaga" University of Sibiu, Department of Agricultural Sciences and Food Products \\ Engineering, 7-9 Ion Ratiu Street, 550012 Sibiu, Romania \\ 2"Lucian Blaga" University of Sibiu, Department of Environmental Sciences, 5-7 Ion Ratiu Street, \\ 550012 Sibiu, Romania
}

\begin{abstract}
Previous studies showed that non-edible parts of red onion contain large amounts of bioactive compounds. We detailed a process for preparing valuable extracts rich in antioxidant compounds and activities from red onion wastes. The influence of economically relevant variables of conventional and ultrasound-assisted extraction - time and solvent/solid ratio was studied. The content of extracted anthocyanins, phenolics, flavonoids and tannins was superior at relatively short ultrasonication time and 30/1 solvent/solid ratio and higher than that of compounds isolated by conventional procedure. The antioxidant activity significantly increased in ultrasonic extracts prepared at 30/1 ratio for 10 minutes. These findings show that large amounts of pigments and compounds with strong antioxidant activity, useful as natural ingredients and colorants for food or textile industry, can be obtained from red onion wastes.
\end{abstract}

Keywords Red onion wastes, conventional extraction, ultrasound-assisted extraction, anthocyanins, antioxidant activity.

To cite this article: OANCEA S, RADU M, OLOSUTEAN H. Development of ultrasonic extracts with strong antioxidant properties from red onion wastes. Rom Biotechnol Lett. 2020; 25(2): $1320-1327$. DOI: $10.25083 / \mathrm{rbl} / 25.2 / 1320.1327$

*Corresponding author: SIMONA OANCEA, "Lucian Blaga" University of Sibiu, Department of Agricultural Sciences and Food Engineering, 7-9 Ion Ratiu Street, 550012 Sibiu, Romania Tel.: +40269-211338, Fax: +40269-212558

E-mail: simona.oancea@ulbsibiu.ro 


\section{Introduction}

Plant foods contain pharmacologically active compounds of medicinal and nutraceutical values. Among these, polyphenols (anthocyanins, flavonoids, hydroxibenzoic and hydroxycinnamic acids) gained special attention due to their multiple health benefits and abundance in edible and non-edible plants (GHARRAS [1]). They are among the strongest antioxidant compounds (KOWALCZYK \& al [2]).

Efficient extraction of phenolics from the plant matrix is essential when approaching the strategy for the development of safe and high quality products (food ingredients, supplements, pharmaceuticals and cosmetics). The extraction conditions must be selected such as to yield high amounts of targeted compounds and to preserve as much as possible their bioactivities. Anthocyanins are molecules known for their limited stability which is influenced by light, temperature, solvent and $\mathrm{pH}$ (CASTAÑEDAOVANDO \& al [3]). Therefore, special attention must be given to their extraction, analysis and storage. The conventional extraction involves the use of polar organic solvents, such as acetone, methanol, ethanol, water or combinations. Acidified methanol or ethanol solutions (up to $0.1 \% \mathrm{HCl}$ ) have been also used to stabilize the red flavylium cation without significant degradation of acylated anthocyanins (GIUSTI \& al [4]; REVILLA \& al [5]). The extraction can be enhanced by optimization of several experimental parameters - solvent type and concentration, solvent/solid ratio, temperature, time and $\mathrm{pH}$. Considering the various types and chemical compositions of plant materials, it is highly recommended to individually design the strategy of extraction of valuable natural products. When extraction is operated at industrial scale, conventional methods may have several disadvantages, such as low recovery of compounds, long extraction time, intensive heating and/or mixing, resulting in high energy consumption with a negative environmental impact. Several non-conventional and hybrid extraction techniques have been described in the literature, such as ultrasound-assisted extraction (UAE) (VINATORU [6]), pressurized liquid extraction (PLE) (JU \& al [7]; FEUEREISEN \& al [8]) and supercritical fluid extraction (SPE) (BLEVE \& al [9]; MARAN \& al [10]) with more or less success regarding the extraction yield, depending on the chemical properties and behaviour of specific compounds (anthocyanins are heat-sensitive water-soluble compounds).

In addition to medicinal herbs, fruits, flowers, leaves and vegetables, alternative resources of polyphenols for instance agro-industrial by-products and wastes may be considered. Vegetable waste and loss comes from agricultural production, postharvest handling/processing and household refuse. Among horticultural crops, onion can lead to large amounts of plant wastes remaining mainly in the form of outer leaves. The 2011 EU report showed that more than 500,000 tonnes of onion wastes (skins, outer fleshy scales, roots) were generated (KOSSEVA \& al [11]) representing over $8 \%$ of the onions production in EU. It has been reported that the outer skins (non-edible parts) of the
Pearl, Red, Yellow and White onion varieties contain six times higher amounts of phenolics than the corresponding flesh of onions (edible parts) based on dry mass (ALBISHI $\&$ al [12])

The aim of the present study was the investigation of optimal extraction conditions of polyphenolic compounds, such as pigments (anthocyanins), flavonoids and tannins from dry outer skins of red onion (Allium cepa L.). This resource was selected because it is a cheap material generated from agriculture and food processing industry. Conventional and ultrasound-assisted extractions under different experimental parameters (solvent/solid ratio, extraction time, temperature) were approached. Total antioxidant activities of the crude extracts were also investigated.

\section{Materials and methods}

\section{Plant material and chemical reagents}

Red onions (Allium cepa L.) of medium size were purchased from a local market (Sibiu, Romania). The completely dry purplish red layers of red onions were manually collected. Approximately $100 \mathrm{~g}$ material was grounded into powder (Grindomix GM 200, Retsch, Germany). The average moisture content was $11.51 \%$ as determined at $105^{\circ} \mathrm{C}$ using the moisture analyzer (MAC 210/NP Radwag, Poland).

Chemical reagents of analytical grade without further purification were used.

\section{Extraction procedures}

The experiment was conducted such as to simultaneously extract anthocyanins, flavonoids and tannins by using $70 \%$ aqueous ethanol. Previous studies on onion wastes reported the use of $35-60 \%$ ethanol solution (KHIARI \& al [13]), 90\% acidified ethanol solution (ŠKKERGET \& al [14]) and 90\% aqueous glycerol (KATSAMPA \& al [15]). Additionally, we have investigated different solvent/sample ratios, much lower than previously reported, based on the requirement for low solvent consumption.

Conventional extraction. Conventional extraction was performed by mixing the sample powder with $70 \%(\mathrm{~V} / \mathrm{V})$ ethanol solution at $40^{\circ} \mathrm{C}$. The experimental conditions were set for two different solvent/sample ratios, 30/1 and 20/1, respectively, and three extraction times $(30,60$ and 90 minutes).

Ultrasound-assisted extraction (UAE). The ultrasound-assisted extraction was performed in $70 \%$ (V/V) ethanol solution using an ultrasonic device (Sonifier SLPe-150, Branson, USA) of $150 \mathrm{~W}$ power and $40 \mathrm{kHz}$ frequency, equipped with a transducer. The pulse duration and pulse interval was set at 5 and $5 \mathrm{~s}$. The solvent/sample mixtures at 30/1 and 20/1 ratio were irradiated in pulsed mode for five predetermined extraction times $(5,10,15,20$ and 25 minutes) at $70 \%$ ultrasonic amplitude. The final temperature of each mixture was measured using an electronic digital thermometer (MultiLong 300).

The experimental design of the extraction process is indicated in Table 1. 
Table 1. Experimental data of the UAE of bioactives from red onion dry skins, using different combinations of extraction time and solvent/solid ratio

\begin{tabular}{|c|c|c|c|}
\hline $\begin{array}{c}\text { Experimental } \\
\text { run }\end{array}$ & $\begin{array}{c}\text { Solvent/solid } \\
\left(\mathrm{ml} \mathrm{g}^{-1}\right)\end{array}$ & $\begin{array}{c}\text { Extraction time } \\
(\mathrm{min})\end{array}$ & $\begin{array}{c}\text { Final temperature } \\
\left({ }^{\circ} \mathrm{C}\right)\end{array}$ \\
\hline $\mathbf{1}$ & $30 / 1$ & 5 & 34.02 \\
\hline $\mathbf{2}$ & $30 / 1$ & 10 & 43.70 \\
\hline $\mathbf{3}$ & $30 / 1$ & 15 & 51.40 \\
\hline $\mathbf{4}$ & $30 / 1$ & 20 & 55.00 \\
\hline $\mathbf{5}$ & $30 / 1$ & 25 & 57.70 \\
\hline $\mathbf{6}$ & $20 / 1$ & 5 & 36.60 \\
\hline $\mathbf{7}$ & $20 / 1$ & 10 & 45.30 \\
\hline $\mathbf{8}$ & $20 / 1$ & 15 & 52.30 \\
\hline $\mathbf{9}$ & $20 / 1$ & 20 & 55.00 \\
\hline $\mathbf{1 0}$ & $20 / 1$ & 25 & 58.40 \\
\hline
\end{tabular}

After extraction, all samples were centrifuged at $8000 \mathrm{rpm}$ at $4^{\circ} \mathrm{C}$ for 10 minutes using the refrigerated centrifuge (Universal 320, Hettich, Germany). The supernatant was further filtered on $0.45 \mu \mathrm{m}$ PTFE membrane syringe filter. The prepared crude extract was used for the determination of anthocyanins, flavonoids, tannins contents and antioxidant activities.

Total anthocyanins (TA). The content was determined spectrophotometrically by the $\mathrm{pH}$ differential method (GIUSTI \& al [4]). The Specord 200Plus UV-Vis spectrophotometer (Analytik Jena, Germany) was used. The content was expressed as milligram cyanidin-3-Oglucoside (Cyn-3-O-G) equivalents per $100 \mathrm{~g}$ dry mass (mg $\left.100 \mathrm{~g}^{-1} \mathrm{DM}\right)$

Total flavonoids (TF). The content was determined by the aluminum chloride colorimetric method (KUMAR $\&$ al [16]) and expressed as milligram quercetin equivalents per $1 \mathrm{~g}$ dry mass $\left(\mathrm{mg} \mathrm{g}^{-1} \mathrm{DM}\right)$.

Total condensed tannins (TT). The content was determined spectrophotometrically by the vanillin assay (PRICE \& al [17]) and expressed as milligram catechin equivalents per $1 \mathrm{~g}$ dry mass $\left(\mathrm{mg} \mathrm{g}^{-1} \mathrm{DM}\right)$.

\section{Total antioxidant activity assays}

Determination of total phenolics (TP). The content was determined spectrophotometrically according to the Folin-Ciocalteu method (SINGLETON \& al [18]) and expressed in milligram of gallic acid equivalents per $100 \mathrm{~g}$ dry mass (mg GAE $\left.100 \mathrm{~g}^{-1} \mathrm{DM}\right)$.

Antioxidant assay using Ferric Reducing Antioxidant Power (FRAP). The total antioxidant activity of crude extracts was determined by the ferric reducing ability assay described by Benzie (BENZIE \& al [19]). The results were expressed as milligram ascorbic acid per $100 \mathrm{~g}$ dry mass (mg $\left.100 \mathrm{~g}^{-1} \mathrm{DM}\right)$.

Radical scavenging activity (RSA) using 1, 1-Diphenyl2-picryl-hydrazyl (DPPH). The RSA activity of crude extracts was determined by DPPH assay described by BrandWilliams (BRAND-WILLIAMS \& al [20]). The results were expressed as inhibition percentage calculated according to formula: $\operatorname{RSA}(\%)=100 \times\left(\mathrm{A}_{\text {control}}-\mathrm{A}_{\text {sample }}\right) / \mathrm{A}_{\text {control }}$
Statistical analysis. Each extraction was performed in duplicate. Data are presented as average of two replicates, expressed as mean \pm standard deviation. Data processing was performed using statistical testing and correlations by Systat v.12.0 (Systat Software, 2009). The correlation between the content of bioactive compounds and the biological activity was done by calculating the Pearson's correlation coefficient, at the significance level of risk $\alpha \leq 5 \%$ and probability $\mathrm{P} \geq 95 \%$. The differences between 20/1 and 30/1 solvent/solid ratios were statistically compared using the Kruskall-Wallis one-way analysis of variance. Linear and nonlinear models were developed for the content of bioactive compounds related to extraction time, by testing several polynomial equations in STATISTICA v.8.0 (StatSoft Inc., 2010) and retaining the ones explaining the largest amount of variance.

\section{Results and Discussion}

\section{Antioxidant compounds and activity of crude extracts under conventional conditions}

The extraction of biologically active compounds of polyphenolic structure from red onion wastes (dry outer skins) was conducted in ethanol solution in all extraction runs, despite that methanol was reported to better extract such compounds (SINGH \& al [21]). The reason was that ethanol is a safe biodegradable solvent that can be obtained at a low cost and with high purity grade by fermentation of carbohydrates rich-materials. The temperature of $40^{\circ} \mathrm{C}$ was applied in order to increase the extractability of the investigated biomolecules.

The influence of two process conditions - solvent/ solid ratio and extraction time - on the amounts of bioactives extracted from red onion skins was studied. The content of the main antioxidant compounds - TA, TP, TF and TT, according to the set extraction parameters is reported in Table 2. 
Table 2. The contents of TA, TP, TF and TT extracted from red onion skins at $40^{\circ} \mathrm{C}$ under different conventional extraction conditions

\begin{tabular}{|c|c|c|c|c|c|}
\hline \multicolumn{2}{|c|}{$\begin{array}{l}\text { Experimental } \\
\text { conditions }\end{array}$} & \multirow{2}{*}{$\begin{array}{c}\text { Total } \\
\text { anthocyanins } \\
\left(\mathrm{mg} 100 \mathrm{~g}^{-1} \mathrm{DM}\right)\end{array}$} & \multirow[t]{2}{*}{$\begin{array}{c}\text { Total phenolics } \\
\left(\mathrm{mg} \mathrm{GAE} 100 \mathrm{~g}^{-1} \mathrm{DM}\right)\end{array}$} & \multirow[t]{2}{*}{$\begin{array}{c}\text { Total flavonoids } \\
\left(\text { mg quercetin } \mathrm{g}^{-1} \mathrm{DM}\right)\end{array}$} & \multirow[t]{2}{*}{$\begin{array}{c}\text { Total tannins } \\
\left(\mathrm{mg} \text { catechin } \mathrm{g}^{-1} \mathrm{DM}\right)\end{array}$} \\
\hline $\begin{array}{c}\text { Ratio } \\
\left(\mathrm{ml} \mathrm{g}^{-1}\right)\end{array}$ & $\begin{array}{l}\text { Time } \\
(\min )\end{array}$ & & & & \\
\hline $30 / 1$ & 30 & $792.10 \pm 58.72$ & $5936.72 \pm 31.40$ & $121.49 \pm 27.59$ & $124.79 \pm 9.78$ \\
\hline $30 / 1$ & 60 & $754.40 \pm 51.97$ & $5989.45 \pm 133.41$ & $102.56 \pm 14.42$ & $127.35 \pm 13.33$ \\
\hline $30 / 1$ & 90 & $847.47 \pm 34.23$ & $6183.85 \pm 268.96$ & $102.25 \pm 14.70$ & $126.70 \pm 12.89$ \\
\hline $20 / 1$ & 30 & $748.90 \pm 92.01$ & $4655.75 \pm 136.20$ & $93.51 \pm 8.69$ & $136.17 \pm 14.23$ \\
\hline $20 / 1$ & 60 & $765.37 \pm 26.57$ & $4384.01 \pm 87.48$ & $100.91 \pm 21.10$ & $126.59 \pm 11.65$ \\
\hline $20 / 1$ & 90 & $840.34 \pm 22.22$ & $4315.81 \pm 501.25$ & $97.26 \pm 24.94$ & $121.48 \pm 9.50$ \\
\hline
\end{tabular}

The extractability of TP improved with the increase of the solvent/solid ratio (30/1 compared to 20/1) and extraction time (90 minutes compared to 60, 30 minutes). No significant differences regarding the content of TA, TF and TT related to the solvent/solid ratio and time of extraction, were registered.

Total antioxidant activity values of the crude extracts as measured by two different electron-transfer based assays, FRAP and DPPH, are compared in Table 3. The previously discussed Folin-Ciocâlteu method for the measurement of TP has been also considered an antioxidant assay based on the reducing capacity of a sample.

The total antioxidant activity by FRAP of crude extracts obtained at 30/1 solvent/solid ratio increased by $45.6 \%$ compared to that of extracts at $20 / 1$ ratio. No differences in total antioxidant values related to the extraction time were observed, by using both assays.

Table 3. The antioxidant and radical scavenging activities of the crude extract of red onion dry skins according to different conventional extraction time and solvent/solid ratio

\begin{tabular}{|c|c|c|c|}
\hline \multicolumn{2}{|c|}{ Experimental conditions } & \multirow{2}{*}{$\begin{array}{l}\text { Total antioxidant activity } \\
\text { (FRAP) } \\
\left.\text { (mg ascorbic acid } 100 \mathrm{~g}^{-1} \mathrm{DM}\right)\end{array}$} & \multirow{2}{*}{$\begin{array}{c}\text { Radical scavenging activity } \\
\text { (DPPH) } \\
(\%)\end{array}$} \\
\hline $\begin{array}{c}\text { Ratio } \\
\left(\mathrm{ml} \mathrm{g}^{-1}\right)\end{array}$ & $\begin{array}{l}\text { Time } \\
(\mathrm{min})\end{array}$ & & \\
\hline $30 / 1$ & 30 & $3310.97 \pm 124.27$ & $82.87 \pm 0.87$ \\
\hline $30 / 1$ & 60 & $3270.46 \pm 117.70$ & $82.33 \pm 1.33$ \\
\hline $30 / 1$ & 90 & $3312.26 \pm 56.41$ & $82.67 \pm 1.17$ \\
\hline $20 / 1$ & 30 & $2252.89 \pm 96.04$ & $86.26 \pm 1.26$ \\
\hline $20 / 1$ & 60 & $2299.71 \pm 74.04$ & $87.36 \pm 0.36$ \\
\hline $20 / 1$ & 90 & $2240.46 \pm 59.71$ & $86.60 \pm 0.60$ \\
\hline
\end{tabular}

\section{Optimal conditions by pulsed ultrasound-assisted extraction (UAE)}

The UAE solid-liquid extraction was performed using $70 \%(\mathrm{~V} / \mathrm{V})$ ethanol. The parameters of the ultrasonic device were $150 \mathrm{~W}$ power, $40 \mathrm{kHz}$ frequency and $70 \%$ ultrasonic amplitude. The influence of different process variables on the responses of TA, TP, TF, TT contents and of antioxidant activities (FRAP, DPPH) was investigated. Consequently, two solvent/solid ratios (30/1 and 20/1) and five extraction time points $(5,10,15,20$ and 25 minutes) were applied.
The linear and nonlinear models processed from the values of the bioactive compounds content related to their extraction time at two different solvent/sample ratios are presented in Figure 1.

The mathematical modeling showed that the exponential relation best fits the data on TA and TP contents related to UAE time, for both ratios, while the linear regression model best suits to data on TF and TT contents. The equations of the mathematical models are presented in Table 4.

Table 4. Equations (mathematical models) and statistical parameters indicating the effect of time on the UAE extraction of bioactive compounds from red onion dry skins

\begin{tabular}{|l|l|l|c|}
\hline Response & Solvent/solid & \multicolumn{1}{|c|}{ Equation } & $\mathbf{R}^{\mathbf{2}}$ \\
\hline TA & $30 / 1$ & $y=494.618+209.253^{*} \log (x)$ & 0.992 \\
\cline { 2 - 4 } & $20 / 1$ & $y=819.138+96.0681^{*} \log (x)$ & 0.471 \\
\hline \multirow{3}{*}{ TP } & $30 / 1$ & $y=7111.77+794.536 * \log (x)$ & 0.942 \\
\cline { 2 - 4 } & $20 / 1$ & $y=5954.33+702.538^{*} \log (x)$ & 0.918 \\
\hline \multirow{2}{*}{ TF } & $30 / 1$ & $y=91.4643+2.14803^{*} x$ & 0.908 \\
\cline { 2 - 4 } & $20 / 1$ & $y=90.5574+1.33643 * x$ & 0.977 \\
\hline TT & $30 / 1$ & $y=133.614+0.88095^{*} x$ & 0.670 \\
\cline { 2 - 4 } & $20 / 1$ & $y=114.832+1.57784 * x$ & 0.993 \\
\hline
\end{tabular}



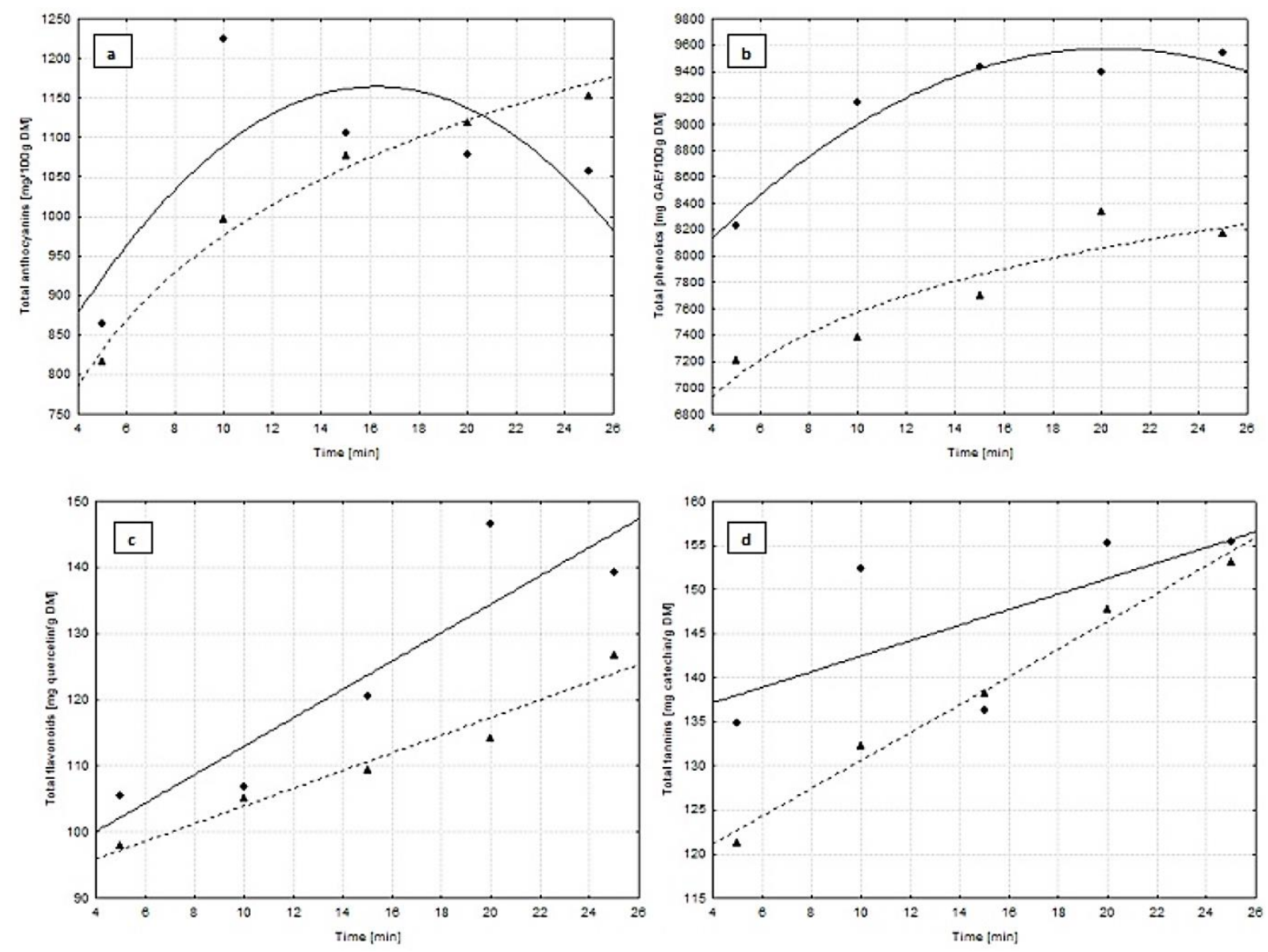

Figure 1. The contents of TA (a), TP (b), TF (c) and TT (d) of the crude extract of red onion dry skins according to different UAE time and solvent/solid ratio (-•-30/1 ratio; -- $\boldsymbol{\Delta}$-- 20/1 ratio).

The TP content increased by $18 \%$ at the $30 / 1$ solvent/solid ratio compared to that at 20/1 one. In terms of UAE extraction time, the maximum yield was produced between 15 and 25 minutes, in all experiments. This might be linked to the final measured temperature of the mixtures during ultrasonication which increased from $35^{\circ} \mathrm{C}$ after 5 minutes to $58^{\circ} \mathrm{C}$ after 25 minutes. Other authors showed that temperature enhances the extraction of total phenolics in mulberry extracts up to $65^{\circ} \mathrm{C}$ (RADOJKOVIĆ \& al [22]). The ultrasonic device was operated in the "time mode with pulse" with a pulse duration and interval of 5 and $5 \mathrm{~s}$, in order to avoid a sharp increase of temperature which may affect the stability of other valuable compounds, in particular anthocyanins.

Several published results on red onion skins extracts reported the isolation of phenolic compounds (KHIARI \& al. [13]; ŠKERGET \& al [14]) under various experimental conditions, such as extraction method (conventional, sonication or combined sonication with maceration), different ultrasonic devices, number of extraction steps, solvents, $\mathrm{pH}$, time, temperature, solvent/solid ratios or envisaged chemical compounds (quercetin). In addition, the type/origin of plant material and its preparation influences the bioactive compounds levels. In the optimization study of Jang (JANG \& al [23]), ethanol extracts of red onions obtained by sonication produced higher yields of quercetin at $49^{\circ} \mathrm{C}$ and $59 \%$ ethanol concentration (both defined as critical factors through the Plackett-Burman experiment) at 60/1 solvent/solid ratio and extraction time of 35 minutes. In another Box-Behnken optimization study (KATSAMPA $\&$ al [21]), 90\% aqueous glycerol extracts of red onions produced higher TP $\left(61.47 \pm 14.19 \mathrm{mg} \mathrm{GAE} \mathrm{g}^{-1} \mathrm{DM}\right)$ and total pigments $\left(1.87 \pm 0.39 \mathrm{mg} \mathrm{CyE} \mathrm{g}^{-1} \mathrm{DM}\right)$ content under optimal sonication conditions using $90 / 1$ solvent/solid ratio at $45^{\circ} \mathrm{C}$ for 60 minutes. Lower solvent/solid ratio such as 20/1 has been also reported by other authors (ŠKKERET \& al [14]) as optimal for the recovery of TP using an ultrasonic bath and extraction time of $2 \mathrm{~h}$. Our results showed similar or higher TP recovered from non-edible parts of red onions by using shorter UAE time and lower solvent/solid ratio (30/1). Considering that solid red onion wastes are low cost materials, the optimal ratio found by us is more effective from the practical point of view, as higher volumes of solvent lead to increased cost of further operations involving the extract and generate further great amounts of wastes. Compared to other results, our investigation reported an extended study to several other types of antioxidant compounds, such as anthocyanins, flavonoids and tannins which may be successfully isolated from red onion skins.

This technique increased TA and TP recoveries by $32.5 \%$ and $61.2 \%$, respectively as compared to conventional 
method. Further, we have performed an estimation of TA, $\mathrm{TP}, \mathrm{TF}$ and TT contents for longer UAE extraction times 30, 60 and 90 minutes (similar to conventional extraction) based on the equations described in Table 4 . The results showed no significant content increase with time. However, higher values were generated as compared to those for conventional extraction at similar treatment times.

\section{Antioxidant activities of ultrasonic crude extracts. Correlation coefficients}

The in vitro antioxidant activity of ultrasonic extracts of red onion wastes was measured using three different analytical assays, based on electron-transfer reactions, as follow: (i) FRAP; (ii) DPPH; (iii) TP content by FolinCiocalteu method (previously discussed). The results are presented in Figures 2-3.

The total antioxidant activities as measured by TP (Figure 1b) and FRAP (Figure 2) showed significantly increased values $(\mathrm{p}=0.02)$ when UAE extraction was done at $30 / 1$ solvent/solid ratio compared to $20 / 1$. The radical scavenging activity as measured by DPPH (Figure 3) indicated significantly lower values $(\mathrm{p}=0.01)$ for UAE extracts at 30/1 solvent/solid ratio.

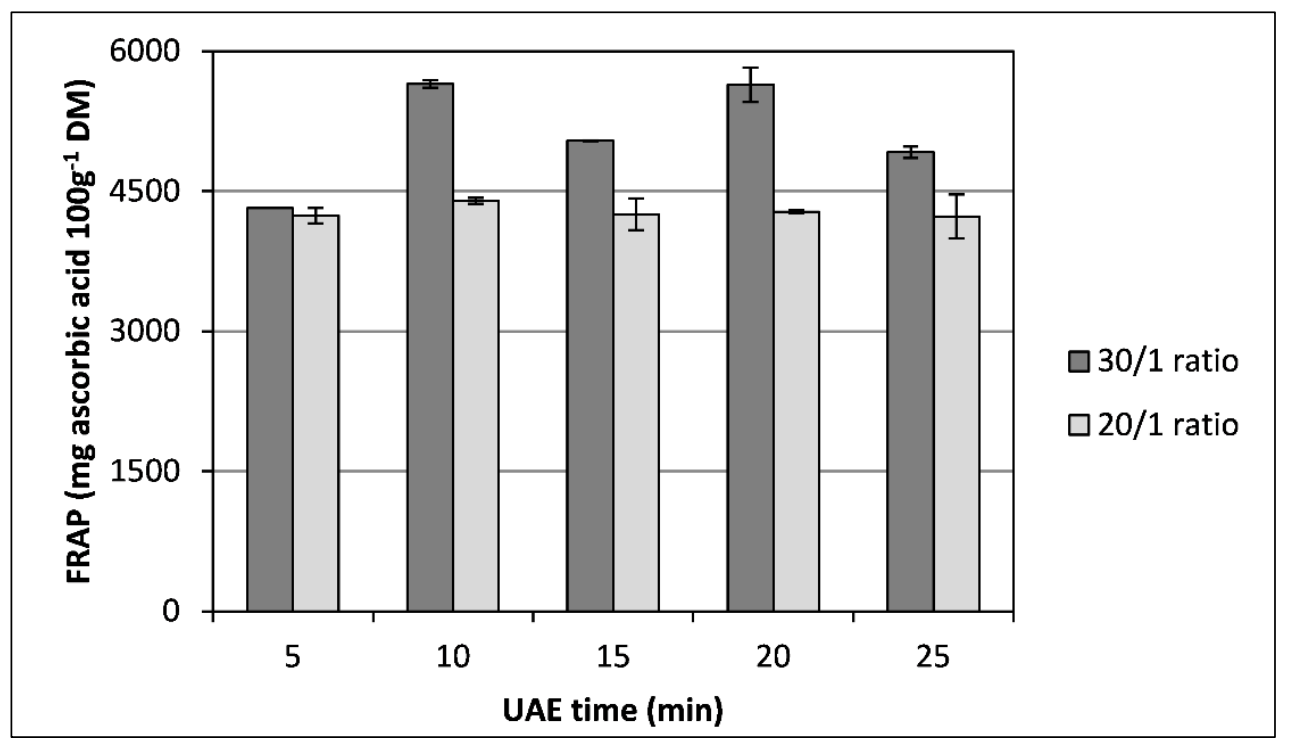

Figure 2. Ferric reducing antioxidant power (FRAP) of the crude extract of red onion dry skins according to different UAE time and solvent/solid ratio; the bar graph illustrates the mean of FRAP values with error bars representing the standard deviation.

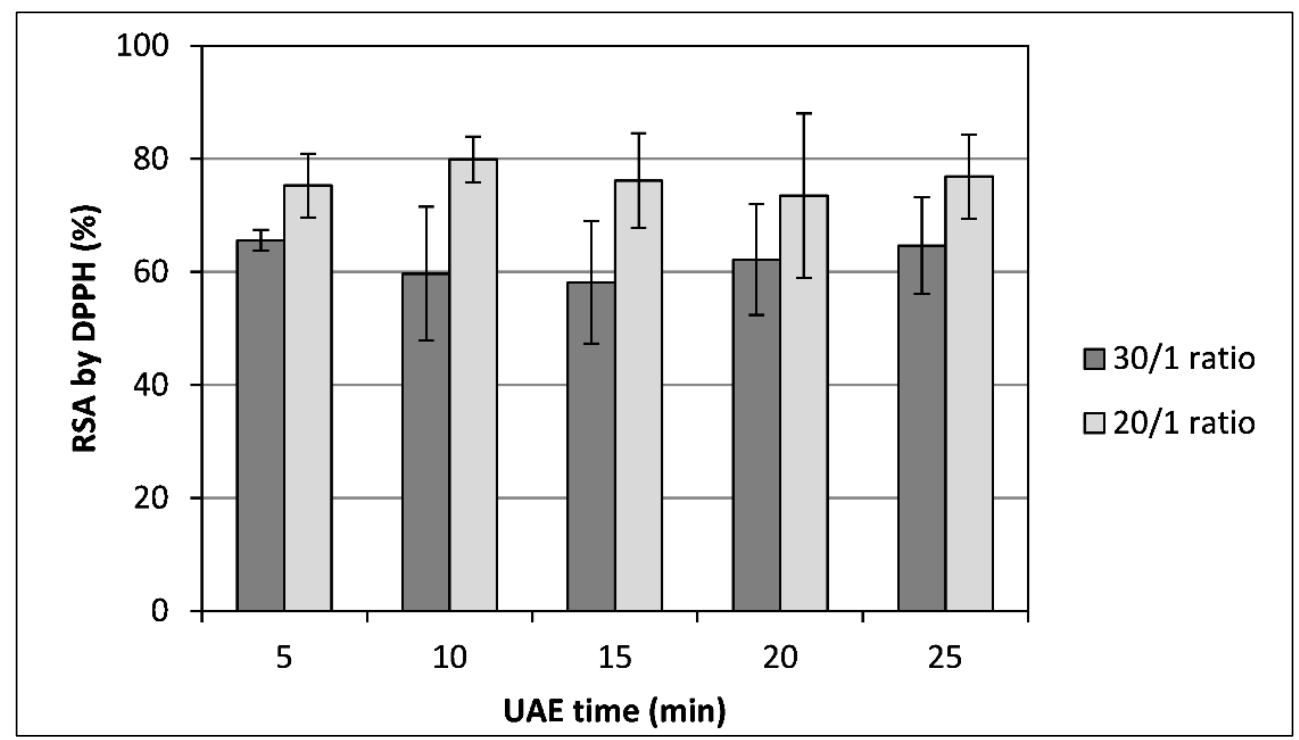

Figure 3. The radical scavenging activity by DPPH method of the crude extract of red onion dry skins according to different UAE time and solvent/solid ratio; the bar graph illustrates the mean of DPPH values with error bars representing the standard deviation. 
Regarding the influence of UAE time on antioxidant activity of extracts, we found that 10 minutes are sufficient for producing increased FRAP values at both ratios and higher DPPH values at 20/1 ratio; longer extraction time produced similar or lower values.

The FRAP activity of ultrasonic extracts increased by
$68.8 \%$ compared to conventional extracts.

The Pearson's correlation coefficients between antioxidant activities (FRAP, DPPH) and contents of bioactive compounds (TA, TP, TF, TT) were used to describe the linear association between these variables. The results are presented in Table 5.

Table 5. The significance of Pearson's correlation coefficients of the antioxidant contents and activities of ultrasonic extracts of red onion dry skins

\begin{tabular}{|l|l|l|l|l|l|}
\hline & TA & TF & TP & TT & FRAP \\
\hline TF & $0.55^{*}$ & & & & \\
\hline TP & 0.40 & $0.72^{* *}$ & & & \\
\hline TT & $0.76^{* * *}$ & $0.71^{* *}$ & $0.76^{* * *}$ & & \\
\hline FRAP & 0.49 & $0.80^{* * *}$ & 0.49 & 0.54 & \\
\hline DPPH & -0.25 & $-0.86^{* * *}$ & -0.36 & -0.35 & $-0.77 * * *$ \\
\hline
\end{tabular}

$*$ significant $(\mathrm{p}<0.10)$

$* *$ very significant $(\mathrm{p}<0.05)$

$* * *$ extremely significant $(\mathrm{p}<0.01)$

The antioxidant activities by FRAP and DPPH were both significantly correlated with TF. The DPPH was significantly but negatively correlated with FRAP and TF, meaning that the lower its value, the higher the ferric reducing power and the TF content. Several studies have shown that polyphenols may act as pro-oxidants in high doses or under particular conditions, which may explain the negative correlation with DPPH scavenging activity (YORDI \& al [24]). The pro-oxidant effect was linked to the anti-cancer properties. Regarding the correlations between the four antioxidant compounds contents of ultrasonic extracts, very significant correlation of TP and TT with TF, and extremely significant correlation between TA and TT was found in the present study.

Other studies reported similar results showing that the antioxidant activity of red onion extracts is more attributed to the TF than to the TP content (SELLAPPAN \& al [25]). Literature reported both positive (ŠKERGET \& al [14]) and negative correlations between DPPH antiradical activity of various plant extracts and any of the FRAP, TP or TF values (TEIXEIRA \& al [26]), and positive correlation with ABTS method (AL-LAITH \& al [27]).

Considering that conventional extraction of anthocyanins, phenolics, tannins and flavonoids requires either long extraction time or increased temperature, which may lead to the decomposition of particular compounds, the extraction assisted by ultrasounds becomes more promising for enhancing their extractability. Our results may be extended to different red onion varieties, as ultrasonication improved the extraction of the hereby studied antioxidant compounds which are abundantly found in all varieties. In order to extend our results to other crops, the extraction variables have to be ascertained for each type of plant material and for the intended chemical compound.

\section{Conclusions}

The present study investigated the effect of conventional and ultrasonic extraction on the bioactive content and antioxidant properties of red onion wastes.

The results showed evidence of high bioactive compounds recoveries using relatively short ultrasonic extraction time (15-25 minutes) and reasonable solvent/ solid ratio (30/1). These findings show an economically efficient extraction considering the low cost of waste material and the use of relatively low solvent volumes that will not increase the cost of further operations involving the extract. We also found that lower UAE extraction time (10 minutes) might be sufficient for producing higher antioxidant activity. Very significant correlations were obtained between total phenolics/tannins and total flavonoids, and extremely significant correlation between total anthocyanins and tannins. The antioxidant activity by FRAP and DPPH assays were both significantly correlated with total flavonoids.

The ultrasound assisted extraction indicated higher amounts of recovered bioactive compounds and activities compared to conventional method, in all experimental runs and estimation calculations.

The obtained results may be of interest for food and non-food manufacturers. Additionally, such approach will assist to the utilization of crop wastes and losses other than composting and incinerating, for the development of bioextracts suitable for pharma market, food, textile or cosmetic industry. Further investigations concerning the stability and toxicity of ultrasonic extracts described above are ongoing to achieve such applications. 


\section{References}

1. GHARRAS HE. Polyphenols: food sources, properties and applications - a review, Int. J. Food Sci. Technol., 44, 2512, 2518 (2009).

2. KOWALCZYK E, KRZESINSKI P, KURA M, SZMIGIEL B, BLASZCZYK J. Anthocyanins in medicine. Pol. J. Pharmacol., 55, 699, 702 (2003).

3. CASTAÑEDA-OVANDO A, PACHECO-HERNÁNDEZ MDL, PÁEZ-HERNÁNDEZ ME, RODRÍGUEZ JA, GALÁN-VIDAL CA. Chemical studies of anthocyanins: A review. Food Chem., 113, 859, 871 (2009).

4. GIUSTI MM, WROLSTAD RE. Current Protocols in Food Analytical Chemistry, John Wiley \& Sons Inc., New York (2001).

5. REVILLA E, RYAN J-M, MARTIN-ORTEGA G. Comparison of several procedures used for the extraction of anthocyanins from red grapes. J. Agric. Food Chem., 46, 4592, 4597 (1998).

6. VINATORU M. An overview of the ultrasonically assisted extraction of bioactive principles from herbs. Ultrason. Sonochem., 8, 303, 313 (2001).

7. JU ZY, HOWARD LR. Effects of solvent and temperature on pressurized liquid extraction of anthocyanins and total phenolics from dried red grape skin. J. Agric. Food Chem., 51, 5207, 5213 (2003).

8. FEUEREISEN MM, GAMERO BARRAZA M, ZIMMERMANN BF, SCHIEBER A, SCHULZEKAYSERS N. Pressurized liquid extraction of anthocyanins and biflavonoids from Schinus terebinthifolius Raddi: A multivariate optimization. Food Chem., 214, 564, 571 (2017).

9. BLEVE M, CIURLIA L, RESCIO L. Supercritical carbon dioxide extracts from red fruits: a "natural" cosmeceutical application. NutraCos., 4, 23, 26 (2005).

10. MARAN JP, PRIYA B, MANIKANDAN S, Modeling and optimization of supercritical fluid extraction of anthocyanin and phenolic compounds from Syzygium cumini fruit pulp. J. Food Sci. Technol., 51, 1938, 1946 (2014).

11. KOSSEVA MR. Sources, characterization and composition of food industry wastes., In: Kosseva MR, Webb C (eds.) Food industry wastes - assessment and recuperation of commodities, Academic Press, Elsevier, pp. 37 (2013).

12. ALBISHI T, JOHN JA, AL-KHALIFA AS, SHAHIDI F. Antioxidative phenolic constituents of skins of onion varieties and their activities. J. Funct. Foods, 5, 1191, 1203 (2013).

13. KHIARI Z, MAKRIS DP, KEFALAS P. An investigation on the recovery of antioxidant phenolics from onion solid wastes employing water/ethanolbased solvent systems. Food Bioprocess. Tech., 2, 337, 343 (2009).

14. ŠKERGET M, MAJHENIČ L, BEZJAK M, KNEZ Ž. Antioxidant, radical scavenging and antimicrobial activities of red onion (Allium cepa $\mathrm{L}$ ) skin and edible part extracts. Chem. Biochem. Eng. Q., 23, 435, 44 (2009).

15. KATSAMPA P, VALSAMEDOU E, GRIGORAKIS S, MAKRIS DP. A green ultrasound-assisted extraction process for the recovery of antioxidant polyphenols and pigments from onion solid wastes using BoxBehnken experimental design and kinetics. Ind. Crops Prod., 77, 535, 543 (2015).

16. KUMAR S, KUMAR D, MANJUSHA K, SAROHA N, SINGH B, VASHISHTA B. Antioxidant and free radical scavenging potential of Citrullus colocynthis (L.) Schrad. methanolic fruit extract. Acta Pharm., 58, 215, 220 (2008).

17. PRICE ML, VAN SCOYOC S, BUTLER LG. A critical evaluation of the vanillin reaction as an assay for tannin in sorghum grain. J. Agric. Food Chem., 26, 1214, 1218 (1978).

18. SINGLETON VL, ROSSI JR JA. Colorimetry of total phenolics with phosphomolybdic-phosphotungstic acid reagents. Am. J. Enol. Vitic., 16, 144, 158 (1965).

19. BENZIE FFI, STRAIN JJ. The ferric reducing ability of plasma (FRAP) as a measure of "antioxidant power": the FRAP assay. Anal. Biochem., 239, 70, 76 (1996).

20. BRAND-WILLIAMS W, CUVELIER ME, BERSET C. Use of a free radical method to evaluate antioxidant activity. LWT-Food Sci. Technol., 28, 25, 30 (1995).

21. SINGH V, KRISHAN P, SHRI R. Extraction of antioxidant phytoconstituents from onion waste. J. Pharmacogn. Phytochem., 6, 502, 505 (2017).

22. RADOJKOVIĆ M, ZEKOVIĆ Z, JOKIĆ S, VIDOVIĆ S. Determination of optimal extraction parameters of mulberry leaves using Response Surface Methodology (RSM). Rom. Biotechnol. Lett., 17(3), 7295, 7308 (2012).

23. JANG M, ASNIN L, NILE SH, KEUM YS, KIM HY, PARK SW. Ultrasound-assisted extraction of quercetin from onion solid wastes. Int. J. Food Sci. Technol., 48, 246, 252 (2013).

24. YORDI EG, PÉREZ EM, MATOS MJ, VILLARES EU. Antioxidant and pro-oxidant effects of polyphenolic compounds and structure-activity relationship evidence. In: Bouayed J (ed.), Nutrition, well-being and health, Intech, pp. 23-48 (2012).

25. SELLAPPAN S, AKOH CC. Flavonoids and antioxidant capacity of Georgia-grown Vidalia onions. J. Agric. Food Chem., 50, 5338, 5342 (2002).

26. TEIXEIRA TS, VALE RC, ALMEIDA RR, FERREIRA TPS, GUIMARÃES LGL. Antioxidant potential and its correlation with the contents of phenolic compounds and flavonoids of methanolic extracts from different medicinal plants. Rev. Virtual Quim., 9, 1546, 1559 (2017).

27. AL-LAith AA, ALKHUZAI J, FREIJE A. Assessment of antioxidant activities of three wild medicinal plants from Bahrain. Arabian J. Chem., DOI: 10.1016/j.arabjc.2015.03.004 (2015). 